\title{
EDUCAÇÃO EM MUSEUS E INCLUSÃO SOCIAL: AÇÕES EDUCATIVAS E CULTURAIS ESPECÍFICAS PARA PESSOAS COM DEFICIÊNCIA'
}

\author{
Cecília Helena de Salles Oliveira * \\ Denise Cristina Carminatti Peixoto Abeleira **
}

\section{RESUMO}

O artigo procura mostrar o caráter e os desdobramentos de projeto no campo da cultura e da extensão universitárias voltado para $o$ atendimento de pessoas com deficiências, particularmente no espaço museológico oferecido pelo Museu Paulista da USP. Indica de que forma foi possível criar experiências lúdicas e educativas através de materiais pedagógicos e ações preparadas pelo Serviço de Atividades Educativas da instituição.

Palavras-Chave: Museu Paulista da USP. Inclusão Social. Educação.

\section{ABSTRACT}

The article seeks to show the nature and ramifications of the project in the field of culture and the university extension toward the care of persons with disabilities, particularly in the museum space offered by the Museu Paulista da USP. Shows how it was possible to create entertaining and educational experiences through educational materials and activities prepared by the Office of Educational Activities of the institution.

Key Words: Museu Paulista da Universidade de São Paulo. Social Inclusion. Education.

1 Este artigo é resultado de projeto desenvolvido, entre 2007 e 2008, com o apoio da Pró-Reitoria de Cultura e Extensão Universitária. As ações implementadas através dele adquiriram repercussão e hoje constituem objetivo permanente do Serviço de Atividades Educativas do Museu Paulista da USP.

* Professora Titular e atual Diretora do Museu Paulista da USP. ** Mestre em Arqueologia pelo MAE-USP e Supervisora do Serviço de Atividades Educativas do Museu Paulista da USP. 


\section{INTRODUÇÃO}

O Museu Paulista da USP, mais conhecido como Museu do Ipiranga, por meio de seu Serviço de Atividades Educativas (SAE-MP), tem procurado desenvolver ações que ofereçam ao público visitante uma fruição mais adequada, prazerosa e profunda de seus espaços expositivos. Para isso, vem estabelecendo, desde 2001, uma série de programas que procuram respeitar as especificidades de cada público que busca a instituição, desenvolvendo materiais e estratégias de mediação comprometidos com a formação plena do indivíduo (UNESCO, 1990). Dentre esses programas, destacamse aqueles voltados para a inclusão sociocultural, tais como: Programa de Orientação ao Professor (POP), Programa de Inclusão para Pessoas com Deficiência (PIMP); Programa para Crianças em Situação de Risco Social (PROVIC); Programa de Atendimento de Jovens e Adultos (PROJAMP).

Assim sendo, Educação em Museus e Inclusão Social constitui projeto de longo prazo que tem como objetivo principal desenvolver estratégias de atendimento para crianças, jovens e adultos com necessidades educativas especiais: pessoas com deficiência intelectual, física ou que apresentam mobilidade reduzida; deficientes visuais, auditivos ou que sofram de limitações múltiplas; grupos de saúde mental e dependentes químicos. Procura, assim, atender ao crescente apelo da sociedade por ações qualificadas e programas não meramente assistencialistas que incluam pessoas com deficiência ou em situação de risco social (WILDER, 2004; TOJAL, 2007).

Por outro lado, essa proposta vincula-se aos demais programas desenvolvidos pelo Serviço de Atividades Educativas destinados a oferecer acesso às exposições, aos bens culturais e aos conhecimentos abrigados e desenvolvidos no Museu Paulista, bem como ampliar as formas de socialização do conhecimento científico desenvolvido por seu corpo técnico-científico. Nesse sentido, o projeto e as ações que promoveu fundamentamse na construção de relações crítico-reflexivas com a realidade histórica e patrimonial estudada pela instituição, bem como na recuperação da auto-estima, no estímulo à capacidade de criação e no desenvolvimento de sensibilidades junto a públicos nem sempre lembrados e atendidos por organismos de natureza cultural (BITTENCOURT, 2005; MARQUES, 2005).

\section{DESENVOLVIMENTO DA PROPOSTA}

Primeiramente, para a realização dos atendimentos e das ações de inclusão social foram estabelecidos contatos com instituições sem fins lucrativos que tratam desses segmentos e que têm caráter socioeducativo, comunitário ou filantrópico. Os grupos foram constituídos conforme suas especificidades e as visitas tiveram duração variável, conforme as características de cada instituição. Isso se explica pelo cuidado que se procurou ter em respeitar as singularidades, necessidades e potencialidades de cada grupo, a fim de não oferecer algo homogeneizado que empobreceria a experiência individual de cada participante (TOJAL, 1999; SARRAF, 2004).

Para se garantir essa qualidade e o desenvolvimento das ações, foram preparados 4 (quatro) bolsistas, alunos de graduação da USP, vinculadas à área das Humanidades, para atuarem junto a esse perfil de público. Os bolsistas, coordenados pela educadora responsável pelo Serviço, Denise Peixoto Abeleira, e assessorados pelo corpo técnico-científico da instituição, estudou, planejou e atendeu de diferentes maneiras diversos grupos procurando oferecer àqueles com deficiência, experiências significativas que os aproximassem da instituição cultural.

\section{OBJETIVOS PRINCIPAIS}

O desenvolvimento dessas ações, em consonância com as propostas da Universidade no que diz respeito à extensão de serviços à comunidade, visou principalmente:

- Promover a inclusão da pessoa com deficiência em espaços culturais;

- Oferecer experiências de qualidade que envolvessem conhecimento e lazer no espaço do Museu;

- Permitir o acesso e a democratização dos conhecimentos e bens culturais da sociedade, por meio da apropriação do patrimônio histórico conservado pelo Museu;

- Fortalecer a participação social e a formação para a cidadania;

- Ampliar a ação social do Museu na comunidade;

- Formar públicos de museus;

- Oferecer formação acadêmica complementar ao aluno bolsista, sensibilizando-o e capacitando-o para atuar em um museu universitário, e em particular, no desenvolvimento de ações culturais para públicos especiais. 
$\mathrm{Na}$ fase inicial, impetraram-se esforços no programa de formação do bolsista. Esse, além de ser um pressuposto importante, já que a bolsa objetivava a formação complementar do graduando, permitindolhe desenvolver outras habilidades e competências para seu futuro exercício profissional, deveria atender às particularidades do projeto, relacionadas ao seu público-alvo. Várias questões precisavam ser cuidadosamente apresentadas e apreendidas pela equipe e era imprescindível garantir que esses estariam preparados para oferecer aos grupos atendidos, experiências significativas e de qualidade (MENDES, 2002).

Para isso, foi necessário levar em consideração a heterogeneidade do público-alvo. O senso comum ainda vê, de maneira equivocada, as ações educativas em Museus. Acredita-se, muitas vezes, que basta dar informações corretas sobre o que está exposto, para que a visita seja satisfatória, tomando apenas o cuidado em adequar a linguagem utilizada para cada faixa etária. No caso de pessoas com deficiência, embora várias experiências estejam sendo realizadas com sucesso, em diferentes instituições, ainda há muito que desenvolver, para que se tornem referenciais seguros. Também não há pesquisas de longo prazo, pelo menos no Brasil, que assegurem as linhas de trabalho mais adequadas a cada tipo de deficiência a serem seguidas por museus de História. Entende-se que para múltiplos perfis e, portanto, distintas necessidades, diferentes abordagens devam ser empregadas para melhor atendê-las. Assim, um intenso programa de leituras e discussões de textos foi estabelecido, buscando dar à equipe os referenciais básicos tanto das questões relacionadas aos temas do Museu Paulista quanto às questões de inclusão e trabalho com pessoas com deficiência (GRACIANI, 2001; WILDER, 2004).

Na segunda etapa, focou-se a atenção na preparação de "atividades-modelo", centrando-se nas parcerias estabelecidas com a Secretaria Municipal da Pessoa com Deficiência e Mobilidade Reduzida, por meio do Projeto Arte Inclui e com a Fundação Casa (antiga FEBEM), por meio do Projeto Amigos da CASA. Embora esse grupo não fosse composto por pessoas com deficiência, o perfil estava associado às demais preocupações do projeto, no que tange às questões referentes à inclusão sociocultural, já que este segmento de público é formado por adolescentes em situação de risco social, oriundos de camadas menos favorecidas da sociedade e, muitas vezes, institucionali- zados por terem cometido delitos. Ao permanecerem sob guarda do Estado, precisam vivenciar experiências que vão além de medidas meramente punitivas, mas que realmente conduzam para a socialização. Assim, o universo do Museu se abre como possibilidade para criar novos referenciais de identidade e pertencimento, posto que a instituição trabalha, entre outros aspectos, com as heranças culturais da sociedade.

Já o Programa Arte Inclui, disponibiliza transporte e alimentação para escolas, entidades e instituições que atendem pessoas com deficiência, criando condições para que pudessem participar da visita orientada no $\mathrm{Mu}-$ seu. Em alguns casos, foi possível desenvolver uma atividade de sensibilização, na própria instituição, despertando o participante para o universo do Museu e suas temáticas (MENESES, 1995; MUSEU PAULISTA, 1995).

Assim, procurou-se estimular o visitante para o universo cultural que o Museu apresenta por meio de suas exposições e propiciar vivências que favorecessem a ampliação de suas experiências educativas e de lazer (HIRATA, 1989; HOOPER-GREENHILL, 1996). Essas atividades, experimentadas e modificadas à medida que novos elementos iam sendo agregados, referenciaram-se na perspectiva segundo a qual as diferentes tipologias de acervos pertencentes ao Museu (objetos, iconografia, registros impressos, manuscritos e bibliográficos) são fontes de informações e que ao serem investigados permitem reflexões acerca da sociedade que os produziu, assim como a construção de mediações entre o presente vivenciado e um passado imaginado. Para isso, foi utilizado o Kit desenvolvido pelo Serviço Educativo dentro da linha de fomento Programa de Políticas Públicas, mantido pela FAPESP-Vitae ${ }^{1}$. O Kit é composto por:

- Objetos: uma xícara, um pires, uma leiteira e uma pequena tigela (possível recipiente de mesa para colocar lavanda), todos de porcelana; um par de luvas de pelica, um chapéu feminino de tecido, uma máquina fotográfica (aproximadamente 1930), um conjunto de abotoaduras e prendedor de gravatas;

- Iconografia: uma reprodução de fotografia de uma mulher e de um casal (ambas do ateliê de Militão

1 Esse projeto contou com a participação de Andréa Fonseca e Ana Emilia de Paula, que na ocasião atuavam como técnicas de apoio educativo do Serviço de Atividades Educativas do Museu Paulista. 
Augusto de Azevedo); fotografia de um casal (ateliê de Militão Augusto); reprodução de fotografia da Rua XV de Novembro no começo do século 20; reprodução de fotografia da região do Ipiranga, com vistas da linha férrea e do edifício do Museu, na época de sua construção (entre 1885-1890); fotografia do edifício do Museu (atual); reprodução de fotografia (vista panorâmica) da região da Várzea do Carmo;

- Documentação textual: reprodução de Nota Fiscal - Casa Fuchs; reprodução de Propaganda - Casa Fuchs; coletânea de frases sobre os objetos que compõem o Kit, selecionados de livros de Hernani da Silva Bruno e Jorge Americano;

- Material tátil: reprodução em resina - alto-relevo - de trecho da obra: Inundação da Várzea do Carmo, em 1892, de Benedito Calixto; reprodução em resina - relevo - de moeda de 2.000 réis, de 1902; Maquete do Edifício do Museu Paulista (portátil);

- Vídeo sobre o Museu Paulista em Libras (Língua Brasileira de Sinais);

- Textos em Braille: apresentação do Kit e descrições da tela tátil, da moeda, da reprodução de Nota Fiscal e da propaganda da Casa Fuchs;

- Maleta para acondicionamento do Material;

- Maquete do Edifício do Museu Paulista (maiores dimensões e detalhes, disponível para ser manuseada na visita ao Museu);

- Recipientes aromáticos (essência de perfumes e condimentos) para estimulação olfativa, inseridas na segunda fase do projeto.

Como referenciais para a composição do Kit e a elaboração do roteiro de visita foram utilizados os espaços expositivos do Museu e seu acervo, bem como a produção científica de docentes e especialistas da instituição, com ênfase em questões referentes aos modos de vida e às práticas cotidianas na cidade de São Paulo na passagem do século 19 para o 20 (BARBUY, 2001).

Também se buscou criar percursos expositivos que respeitassem as diferentes necessidades, já que grupos de pessoas em cadeiras de rodas não teriam acesso a determinados espaços expositivos, uma vez que o prédio ainda não está adaptado para essa demanda. Assim, sem comprometer os objetivos propostos, definiram-se roteiros específicos para as áreas expositivas que não oferecessem impedimentos de circulação. Cabe destacar que no andar térreo, por exemplo, a exposição "Imagens Recriam a História”, que apresenta eixo conceitual relacionado à linha de pesquisa institucional História do Imaginário, pode ser explorada inclusive por pessoas com deficiência visual, pois dispõe de telas táteis e textos em Braille elaborados de forma articulada às principais questões tratadas e que dizem respeito ao modo pelo qual a História do Brasil e de São Paulo foi construída e representada em suportes visuais de grande impacto, a exemplo das telas de Oscar Pereira da Silva e de Almeida Júnior sobre o processo de colonização e o bandeirismo (MARINS, 2007).

Outro aspecto relevante em relação ao manuseio de objetos encontra-se no fato desse recurso, para além de mera estratégia lúdica, oferecer estímulo significativo para a articulação entre o concreto e o pensar reflexivo (HIRATA, 1989). Ao se disponibilizar materiais para o toque (a partir do Kit e de outros objetos e recursos incluídos posteriormente) permite-se, principalmente para aqueles que possuem algum comprometimento físico ou intelectual, uma aproximação concreta com conceitos muito abstratos (MENESES, 1983).

No decorrer do projeto, procurou-se também experimentar novos materiais para a realização das atividades. Várias tentativas foram feitas tendo em vista a criação de desenhos e textos explicativos em linguagem acessível, principalmente àqueles com déficit cognitivo e também de materiais táteis para pessoas cegas (TOJAL, 2007). De efetivo, produziu-se uma prancha para cegos, que buscava permitir a percepção dos conteúdos apresentados em uma propaganda da Casa Fuchs (estabelecimento comercial da cidade de São Paulo, do final do século 19 e inícios do século 20), que compunha o Kit utilizado. Esse material revelou-se uma ferramenta bastante eficaz para a aproximação e criação de repertório acerca desse tipo de fonte documental.

Ao todo, foram atendidos 33 grupos de diferentes perfis, num total de 680 pessoas (crianças, adolescentes e adultos).

\section{CONSIDERAÇÕES FINAIS}

Inicialmente, é importante relatar que o grande problema enfrentado para o desenvolvimento do projeto 
foi a dificuldade apresentada por várias instituições para deslocarem-se com seus grupos. Por se tratar de instituições governamentais ou sem fins lucrativos, dispõem de poucos recursos e esses são canalizados para as atividades básicas de manutenção e aquelas realizadas nas próprias dependências. Assim, as atividades "extramuros", que necessitam de contratação de ônibus são inviabilizadas. Constatou-se que inúmeras delas se interessaram muito quando o contato foi feito e o projeto apresentado, mas ao saberem que o Museu não ofereceria o transporte, declinavam do convite.

Assim, a solicitação feita pela Secretaria Municipal da Pessoa com Deficiência e Mobilidade Reduzida para que participássemos do programa Arte Inclui veio ao encontro dos anseios do Serviço Educativo. Técnicos da Secretaria agendavam e transportavam as entidades e ficava a critério e responsabilidade da equipe do $\mathrm{Mu}-$ seu o enfoque e desenvolvimento da visita.

Cabe afirmar que a avaliação das atividades demonstra que foi possível propiciar aos visitantes uma experiência bem diferenciada no espaço do Museu. Ficou claro, em cada atendimento, que ainda há um grande desafio a ser percorrido no sentido da inclusão, seja no que diz respeito às estratégias de atendimento e dos materiais de apoio à mediação, seja no que tange às limitações arquitetônicas impostas pelo edifício centenário. Faz-se necessário, e urgente, adaptar o prédio tornando-o acessível a qualquer pessoa.

É importante sublinhar ainda que a maioria quase absoluta dos participantes nunca havia visitado um museu antes. No caso do Museu Paulista, alguns tinham ouvido falar, mas de maneira superficial e equivocada sobre os aspectos básicos dessa instituição. Percebeu-se que além de certo deslumbramento com a arquitetura do edifício, o ponto de destaque era o envolvimento com cada atividade proposta, revelada pelo contato com fontes documentais, pelo percurso nas áreas expositivas e pelas discussões propostas pelos educadores durante o percurso.

Resta agora, uma vez estabelecida a proposta e os materiais de apoio, ampliar o atendimento oferecido para que seja possível desenvolver ampla e profunda pesquisa da relação de ensino-aprendizagem possibilitada pelo espaço do Museu Paulista e experimentar novas metodologias que se revelem adequadas a esse universo.
Nesse sentido, o museu universitário em especial, estará cumprindo sua meta de propiciar à sociedade vivências resultantes de intenso processo de investigação, capazes de ensejar pontes entre o saber construído na academia e aquele que permeia o dia a dia das pessoas que buscam as instituições culturais dessa natureza.

\section{REFERÊNCIAS BIBLIOGRÁFICAS}

BARBUY, Heloisa Maria Silveira. A cidade-exposição: comércio e cosmopolitismo em São Paulo, 1860-1914 (estudo de história urbana e cultura material). Tese de Doutorado, 2001.

BITTENCOURT, Circe Maria Fernandes. Ensino de história: fundamentos e métodos. São Paulo: Cortez, 2005.

GRACIANI, Maria Stela Santos. Pedagogia Social de rua: análise e sistematização de uma experiência vivida. 4⿳亠丷厂犬 edição — São Paulo: Cortez: Instituto Paulo Freire, 2001 — Coleção Prospectiva, v. 4.

HIRATA, Elaine. Farias Veloso e outros “Arqueologia, Educação e Museu: o objeto enquanto instrumento do conhecimento”. In: Dédalo, no 27. São Paulo: MAE-USP, 1989. (pág. 11-46).

HOOPER-GREENHILL, Eilean. Museums and their visitors. London: New York: Routledge, 1996.

MARINS, P. C. G. Nas matas com pose de reis: a representação de bandeirantes e a tradição da retratística monárquica européia. In: Revista do Instituto de Estudos Brasileiros, v. 44, p. $77-104,2007$.

MARQUES, Denise Cristina Peixoto Catunda. Arqueologia e Educação: uma proposta de leitura do patrimônio. São Paulo, USP - Museu de Arqueologia e Etnologia, Dissertação de Mestrado, 2005.

MENDES, Enicéia Gonçalves. Perspectivas para a Construção da Escola Inclusiva no Brasil. PALHARES, Marina Silveira; MARINS, Simone Cristina. Escola Inclusiva. São Carlos: EdUFSCar, 2002, p. 61-85.

MENESES, Ulpiano T. Bezerra de. Do teatro da memória ao laboratório da história: a exposição museológica e o conhecimento histórico. Anais do Museu Paulista, N. série, v. 3, p. 83-84, jan./dez. 1995.

MENESES, Ulpiano T. Bezerra de "A cultura material no estudo das sociedades antigas”. In: Revista de História/USP, no 115, Julho-Dezembro 1983. 
MUSEU PAULISTA. Museu Paulista: Novas leituras / coordenação: Cecília Helena de Salles Oliveira. - São Paulo: Museu Paulista da Universidade de São Paulo, 1995.

SARRAF, Viviane Panelli. A Inclusão das Pessoas com Deficiências Visuais nos Museus: uma análise realizada com base em avaliações sobre acessibilidade. São Paulo: MAE-USP, 2004 (Monografia de Especialização).

TOJAL. Amanda Pinto da Fonseca. Museu de arte e público especial. Dissertação de Mestrado. São Paulo: Escola de Comunicações e Artes, Universidade de São Paulo, 1999.

TOJAL, Amanda Pinto da Fonseca. Políticas Públicas Culturais de Inclusão de Públicos Especiais em Museus. São Paulo: USP, Tese de doutorado, 2007.

UNESCO. Declaração Mundial sobre Educação para Todos Satisfação das Necessidades Básicas de Aprendizagem. Conferência Mundial sobre Educação para Todos, Jomtien, Tailândia, 1990.

WILDER, Gabriela Suzana. Inclusão cultural: uma missão dos museus de arte contemporânea. São Paulo: ECA-USP, 2004. (Tese de Doutorado). 